\title{
Turning Intention Into Behaviour: The Effect of Providing Cues to Action on Participation Rates for Colorectal Cancer Screening
}

\author{
Ingrid Flight ${ }^{1}$, Carlene Wilson ${ }^{2}$ and Jane McGillivray ${ }^{3}$ \\ ${ }^{1}$ CSIRO Preventative Health Flagship, \\ ${ }^{2}$ Cancer Council South Australia and Flinders University, \\ Flinders Centre for Innovation in Cancer, \\ ${ }^{3}$ School of Psychology, Deakin University, \\ Australia
}

\section{Introduction}

Colorectal cancer (CRC) is the third most commonly diagnosed cancer in males and second in females; throughout the world over 1.2 million new CRC cases and 608,7000 deaths are estimated to have occurred in 2008 (Jemal et al., 2011). The only developed country to have demonstrated a significantly decreasing incidence in both males and females is the United States, and this is largely due to the early detection and removal of pre-cancerous lesions through CRC screening (Jemal et al., 2011). Thus, an understanding of the variables that encourage people to participate in CRC screening is important because early detection and treatment of precancerous lesions and adenomas results in a significantly higher survival rate than if treatment is delayed until physical symptoms of the condition are apparent. Population screening using a Faecal Occult Blood Test (FOBT) can facilitate the detection of CRC at its early stages. FOBT is the collective term for a guiaic FOBT (gFOBT) or a faecal immunochemical test (FIT). Both are home-based tests which, although differing in the technology utilised, involve a stool sample being sent to a laboratory to be analysed for occult blood, ideally followed by colonoscopy for those with a positive result. The cost effectiveness of FOBTs for the screening of CRC, measured as Quality Adjusted Life Years gained, is comparable to other screening procedures (Frazier et al., 2000) and more costeffective than treatment after physical symptoms are evident (Fisher et al., 2006). Randomised clinical trials have shown that both biennial and annual screening using FOBT screening reduces CRC incidence (Mandel et al., 2000) and mortality (Hardcastle et al., 1996; Kronborg et al., 2004; Mandel et al., 1993), and a systematic review concluded that FOBT screening is likely to avoid 1 in 6 colorectal cancer deaths (Hewitson et al., 2007). Effectiveness, however, depends upon yield and is critically dependent upon participation rates, which for population-based screening programs have been low, often despite high levels of intention to participate. For example, in Australia the National Bowel Cancer Screening Program, which provides people turning 50, 55 and 60 years with a free FOBT, had a participation rate in 2008 of $41 \%$ of the eligible population (AIHW, 2010). In England, the second round (2003-2005) of the pilot bowel cancer screening program had a 
significantly lower uptake than in the first round (52\% vs 58\%) (Weller et al., 2006) and reported participation rates in 2008 in other countries with an established or pilot population FOBT screening program ranged mostly from a moderate $45-50 \%$ (Italy and Denmark, respectively) to a low 16-18\% (Korean Republic and Japan, respectively) level (International Cancer Screening Network, 2008). Understanding motivators to intention to participate and motivators to test completion are critical issues that need to be addressed.

The central question in research within health psychology is identifying and understanding the range of influences that prompt an individual to take up healthy behaviours or reject patterns of behaviour which compromise their health. Many social cognitive health behaviour models include a measure of intention to behave in a specific way as a precursor to action (e.g., Theory of Planned Behaviour; (Ajzen, 1985). Stage models focus specifically on the importance of addressing intention as a core component of public health interventions. For example, the Transtheoretical, or Stages of Change, Model (Prochaska, 2008; Prochaska et al., 1988) suggests that people can be characterised in terms of their readiness to make a change. Stages include precontemplation (benefits of lifestyle change are not being considered), contemplation (starting to consider change but not yet begun to act on this intention), preparation (ready to change the behaviour and preparing to act), action (making the initial steps toward behaviour change), and maintenance of the behaviour over time; with both contemplation and preparation measuring aspects of intention.

One of the most difficult questions for researchers examining screening participation has been the question of how to move people along these stages to the performance of the actual behaviour and, ideally, maintenance of the behaviour. A range of social cognitive models of health behaviour have proven effective in describing individual motivation to perform a variety of health behaviours, including screening, by identifying a range of attitudinal predictors (Conner \& Norman, 2005). Each of these deliberative models can successfully map variables that describe individual differences in the intention to perform a behaviour. However, the relationship between behavioural intention and actual behaviour is less than perfect; it has been shown that around $50 \%$ of people with positive intentions to engage in health behaviours successfully translate those intentions into action (Sheeran, 2002), and a medium-to-large change in intention leads to only a small-to-medium change in behaviour (Webb \& Sheeran, 2006).

This 'gap', the difference between an individual's commitment to act and initiation of the necessary processes to actually carry out the behaviour, needs to be bridged - in other words, research that influences 'intention to try' (Bagozzi \& Warshaw, 1990) needs to also identify cues that will enable people to link to the means for achieving the intended behaviour. Some health behaviour models incorporate a stimulus to action in their operationalisations in an attempt to capture this intervening, or additive, influence that prompts individuals to actually implement behaviour. For example, Becker and colleagues (1977) incorporated 'cues to action' as additional, independent predictors of health behaviour, over and above attitudinal variables. Although incorporated in the earliest descriptions of the Health Belief Model, a cue to action, or strategy to initiate "readiness", is a variable that has received limited attention in the empirical literature. Nevertheless, research does suggest that certain acts may serve to stimulate health behaviour including physician advice, advertising campaigns, and postcard reminders (Sheeran \& Orbell, 2000).

Research originating outside the health area has examined the notion of volitional control and how it might be used to explain the problematic nature of the relationship between 
behavioural intention and behaviour (Gollwitzer, 1993). This model suggests that individuals achieve volitional control of their intention to act by the development of implementation intentions; the plans made to achieve a specific behavioural target (e.g., a statement describing when, where and how a specific behaviour will be carried out). These plans serve to provide the cue to action identified by the Health Belief Model but go beyond this by providing the plan for goal achievement.

Recent empirical work suggests that the approach of providing cues to action in the form of a specific implementation intention improves prediction of behaviour over and above the intention to act alone. Thus, Milne, Orbell and Sheeran (2002) reported improved exercise participation; Sheeran and Orbell (2000) reported beneficial effects on the uptake of cervical cancer screening; Verplanken and Faes (1999) described improved dietary regimens; and Orbell et al. (1997) cited improved rates of breast self-examination.

A study examining uptake in the National Health Service Breast Screening Program (NHSBSP) in the UK (Rutter et al., 2006) has highlighted the importance of providing guidance on how to plan for a behaviour in order to ensure that people move from intention to actual behaviour (i.e., from the preparation to the action stage of the Transtheoretical Model, TTM). In this study, women invited to screen for breast cancer were asked to make specific plans for attending. The plans consisted of organising their travel, arranging to take time off work if necessary and changing the appointment if it was inconvenient. The results indicated that when women produced a written plan, actual rate of compliance with the screening appointment was $15 \%$ greater than in the control condition (no intervention) and $7 \%$ greater than women who failed to write down a plan although instructed to do so. Moreover, the influence from the production of cues to action in the form of a written plan was greatest for those who initially had a high intention to comply but a weak sense of control over making the necessary arrangements to put that intention into effect. This research suggests that uptake of FOBT might be significantly improved by providing a cue to action that seeks to stimulate people to do more than simply express their intention to screen. An effective informational intervention that results in the development of implementation intentions in the form of a plan describing the when, where, and how of faecal occult blood testing, and which enables the individual to deal with their own personal and environmental constraints, should provide those with the intention to act the further resources necessary for achieving their goal.

One possible mechanism for explaining the effectiveness in previous studies of asking participants to form implementation intentions is that doing so forces people to think through the steps necessary for actually completing the screening. This 'thinking through', in turn, may serve to raise people's confidence about their ability to successfully carry out the screening behaviour. Confidence in one's own capacity to act is known in the literature as 'self efficacy' and is widely reported as predicting health behaviour participation (Schwarzer \& Fuchs, 1995). People's feelings of self efficacy are likely to be a particular consideration in using the FOBT because the test is performed by the individual and not administered, like mammography or Pap smear, by a health care professional. Previous studies looking at consumer-initiated screening behaviours have shown that feelings of confidence in one's ability to correctly perform the behaviour bear a strong relationship to people's performance of these behaviours. This includes performance of breast selfexamination (Luszczynska, 2004), testicular self-examination (Lechner et al., 2002), and FOBT (DeVellis et al., 1990). 


\section{Aims}

This study was designed to investigate the effect of the formulation of implementation intentions upon people's participation in screening using FOBT. We chose to examine uptake of FOBT rather than colonoscopy because, in comparison to the United States, usual CRC screening practice in Australia is by FOBT followed by colonoscopy for those with a positive result-in other words, colonoscopy is regarded as a diagnostic test rather than a screening test.

An additional aim was to monitor the impact upon participation of differing levels of directedness in formulating these intentions and to determine the impact of self efficacy and prior levels of generalised intention upon both implementation intention formation and participation.

Consistent with prior research, it was anticipated that the formulation of implementation intentions (regardless of level of directedness) would increase participation in FOBT over levels of participation in the control group. Furthermore, previous work in the area of preventive health behaviour suggests that people's feelings of self efficacy, or confidence to use the test (the terms 'self efficacy' [SE] and 'confidence' will hereinafter be used interchangeably) can be increased in response to appropriate cues to action, and it was anticipated that the provision of directions for the formulation of implementation intentions would increase people's feelings of self efficacy. It was further hypothesised that those who were already strongly intending to use an FOBT were expected to differ in implementation intention formation and participation from those whose intentions to test were initially weaker.

We conducted two randomised controlled trials to test these hypotheses. Study 1 was a trial conducted amongst a group of eligible, randomly selected males and females who were approached and agreed to participate in the trial. Study 2 was also a randomised controlled trial to examine the generalisability of results to population settings and which differed from Study 1 in that prior commitment to trial participation was not obtained and eligibility was unknown.

\section{Study 1}

\subsection{Methods}

\subsubsection{Study design}

The study was a parallel, randomised, controlled trial, stratified by sex, comparing return of FOBT between three intervention groups and one control group. People in the intervention groups received an FOBT of the immunochemical type (FIT) in the mail together with instructions on how to construct a (1) participant-determined and retained plan, (2) participant-determined and shared plan, or (3) researcher-directed and shared plan. The control group received the FOBT only.

\subsubsection{Sample size and selection}

Previous studies of implementation intentions have demonstrated that the effect of their formation upon behaviour is medium to large (Gollwitzer \& Sheeran, 2006). To achieve statistical power of .80 to detect a medium-sized effect (allowing for the possibility of self efficacy and generalised intention as co-variants) and an alpha of 0.05 , we aimed to recruit a minimum of 80 participants in each of the four groups described above. Accordingly, 
allowing for non-contactability by telephone, a subsequent rejection rate of $30 \%$ and ineligibility, we needed to recruit at least 1600 participants to achieve a final sample size of 320 (160 men and 160 women).

A random sample of 6000 (3000 males, 3000 females) potential invitees aged between 50 and 76 years and residing in southern urban Adelaide, South Australia, was provided by the Australian Electoral Commission (AEC). The Australian Government was conducting a pilot National Bowel Cancer Screening Program (NBCSP) at the same time (2004) so individuals with postcodes within the Federal screening program were deleted from the sample provided.

Telephone contact numbers for the remaining sample were obtained by comparing the list against information contained in the electronic White Pages telephone directory. Those persons for whom telephone contact details were not indicated were excluded from the list, as were those whose address indicated that they resided in a hostel or nursing home; such individuals were unlikely to be in the position of deciding for themselves whether they should screen for CRC. The remaining sample was randomized separately by sex using a random number generator (Microsoft ${ }^{\circledR}$ Office Excel 2003) and 400 (200 m; 200 f) names were assigned sequentially to one of 4 groups. In total 1642 names were allocated.

\subsubsection{Study conduct}

The trial proceeded through a number of phases, as described below and illustrated in Table 1 . Phase 1: All potential participants were mailed an advance notification letter and accompanying information, to the effect that an attempt would be made to contact them by telephone to invite them to participate in a study on how best to encourage people to participate in screening for colorectal cancer. Potential participants were advised that they were ineligible to participate if they had ever participated in CRC screening or been diagnosed with CRC or polyps. This exclusion criterion was because in Australia such diagnoses normally follow a positive FOBT and subsequent colonoscopy, and we wanted to target those who had not displayed overt symptoms but were of average risk (that is, based solely on the fact that they were aged 50 years or more) of developing CRC. An opportunity was provided at this point for individuals to decline participation or to indicate that they were ineligible.

Phase 2: One week after the advance notification letter, attempts were made (to a maximum of 3 occasions) to telephone individuals and recruit them to the study. A Computer Assisted Telephone Interview (CATI) format was used by trained interviewers to collect interview responses (Microsoft (® Office Access 2003). For those who were contactable and agreed to participate, informed consent was formally requested and recorded before commencement of the CATI. The recruiting interviewers were blinded to an individual's group allocation until they reached that part of the CATI (after having determined eligibility) that, as part of obtaining informed consent, provided details of the particular intervention to which the participant had been assigned. To those that agreed to participate, the interviewer briefly described what an FOBT was and asked whether they had heard of it: "Before we contacted you, had you ever heard of a screening test for colorectal cancer, where you are given a set of cards to take home and asked to smear a part of your stool on the cards on two separate occasions, and then return the cards to be tested for blood? This is called a Faecal Occult Blood Test, or FOBT. This is the type of screening test we will be sending you". Baseline measures were obtained: background demographics, level of commitment to using an FOBT, and confidence to use the kit. 


\begin{tabular}{|c|c|c|c|c|}
\hline Phase 1 & $\begin{array}{l}\text { Recruitment } \\
\text { Phase } 2\end{array}$ & $\begin{array}{l}\text { Interventions } \\
\text { Phase } 3\end{array}$ & $\begin{array}{l}\text { Measures } \\
\text { Phase } 4\end{array}$ & $\begin{array}{l}\text { Measures } \\
\text { Phase } 5\end{array}$ \\
\hline $\begin{array}{l}\mathrm{N}=1642 \\
\text { Potentially } \\
\text { eligible } \\
\text { participants } \\
\text { randomised to } \\
\text { study arm then } \\
\text { notification of } \\
\text { intention to } \\
\text { contact by } \\
\text { telephone + } \\
\text { information } \\
\text { sheet mailed }\end{array}$ & $\begin{array}{l}\mathrm{N}=994 \\
\text { contactable. } \\
\mathrm{N}=364 \text { agreed to } \\
\text { participate in } \\
\text { CATI interview: } \\
\text { Baseline measures: } \\
\text { Demographics } \\
\text { Commitment to } \\
\text { screen } \\
\text { Self efficacy to } \\
\text { use FOBT }\end{array}$ & 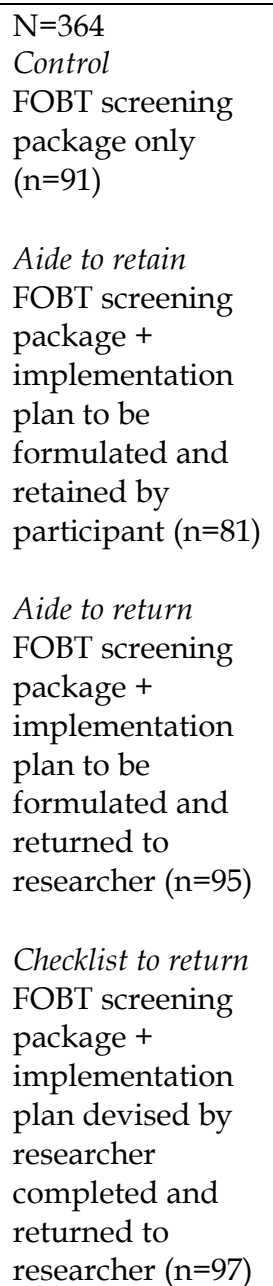 & $\begin{array}{l}\mathrm{N}=350 \\
\text { after } \\
\text { exclusions } \\
\text { (All } \\
\text { groups) } \\
\text { Measures: } \\
\text { Return of } \\
\text { kit within } 6 \\
\text { weeks } \\
\text { Return of } \\
\text { kit after } 6 \\
\text { weeks }\end{array}$ & $\begin{array}{l}\mathrm{N}=328 \\
\text { after } \\
\text { exclusions } \\
\text { (All groups) } \\
\text { CATI } \\
\text { interview } \\
\text { measures: } \\
\text { Commitment } \\
\text { to rescreen } \\
\text { Self efficacy } \\
\text { to use FOBT } \\
\text { Reasons for } \\
\text { not screening } \\
\text { (if applicable) } \\
\text { Reasons for } \\
\text { screening } \\
\text { (if applicable) }\end{array}$ \\
\hline
\end{tabular}

Table 1 . Study 1 interventions by phase and arm, with attrition rates

Phase 3: The day following the recruitment interview, all participants were mailed a screening package which included an immunochemical FOBT. Accompanying the package, intervention groups also received an implementation plan to serve as a 'cue to action' to provide a strategy for goal achievement (completion and return of the FOBT). Two intervention groups received a participant-directed plan in the form of an 'Aide' that invited participants to think about, and write down, how they were going to deal with potential barriers to using the FOBT. Suggestions were made as to how these barriers could be addressed. Participants in one of these two groups were asked to retain their completed plan ('Aide to retain'); the other group were sent two copies of the plan and requested to 
return one copy of the completed plan to CSIRO ('Aide to return'). The third intervention group received a plan in the form of a researcher-directed 'Checklist' ('Checklist to return') which directed participants to think about how they were going to deal with potential barriers. This group was also provided with two copies of the checklist and asked to return one completed checklist to CSIRO. Thus, those in the intervention groups were invited to formulate implementation plans at differing levels of directedness, and the researchers, through their requirement that two of the intervention groups return a completed plan, were able to verify that in fact a plan had been completed. The control group received a screening package without any accompanying plan.

Phase 4: Receipt of completed FOBTs was recorded by the Bowel Health Service (Repatriation General Hospital, Bedford Park, South Australia) and participation data relayed to the researchers. People who did not return their test after six weeks were sent a reminder letter. Participation in screening was defined as receipt of kit within 6 weeks (before reminder) or after 6 weeks.

Phase 5: Approximately 7 weeks following FOBT despatch, participants were contacted by telephone. Confidence to use the FOBT was again measured, as was (for those who had returned their FOBT) commitment to screen every two years in the future, following recommended screening guidelines. Additionally, participants' reasons for screening or not screening were elicited, depending on whether a completed FOBT had been returned at the time of interview (data not included in these analyses).

\subsection{Materials}

\subsubsection{Development of implementation plans}

Two versions of implementation plan were designed; one as an 'aide' and the other as a more prescriptive 'checklist'. Each version was introduced to the participant with the words "Many people find that they intend to complete the FOBT but then forget or 'never get around to it'. It has been found that if you form a definite plan of exactly when and where you will carry out an intended behaviour you are more likely to actually do so and less likely to forget or find that you don't get around to doing it. It would be useful for you to plan when, where and how you will complete the FOBT. To help you do this, we would like you to use the attached sheets we have provided" (adapted from Milne et al., 2002). Both plans were designed to support confidence and addressed practical aspects of completing the test (reading the instructions; deciding the most convenient time to use the FOBT; deciding the most convenient location to use the FOBT; preparing for the test; using the FOBT; remembering to use the FOBT; sending the FOBT for analysis). Both versions commenced with the instruction: "Using this plan, decide when you will use the screening kit, where you will use the kit, and the procedure you will use to carry out the screening test and obtain your result from the Bowel Health Service". They thereafter differed in their level of directedness in covering the practical aspects. For example, for 'remembering to use the kit' the aides contained the following instruction: "It is easy to forget to do things unless we have a way to remind us. Decide now how you can make it easier for you to remember - for example, by leaving the kit or this plan in a prominent location, or writing yourself a note. Write below how you will remind yourself to use the kit on two separate occasions". In contrast, for the same instruction the checklist stated "Place a reminder in a prominent place so that you do not forget to use the kit" with two check boxes (1 ${ }^{\text {st }}$ sample done; $2^{\text {nd }}$ sample done) to indicate that this instruction had been carried out. The complete documents are available from the first author on request. 


\subsubsection{Development of self efficacy scale}

Self efficacy was measured using 4 items derived from terms developed by Vernon et al. (1997) and our clinical experience of the challenges and impediments surrounding FOBT use. Participants were asked to rate their degree of confidence in surmounting the barriers described. The items were scored on a 5-point Likert scale ranging from strongly disagree (1) to strongly agree (5). The items were: "I feel confident that I would be able to carry out an FOBT"; "I feel confident that the test will not be overly distasteful or embarrassing"; I feel confident that I would be able to find time in the day to complete the test"; "I feel confident that I could complete the test correctly". The scale had good internal consistency, with a Cronbach alpha coefficient of .86 .

\subsubsection{Commitment to screen}

Commitment to screen was measured in Phase 2 by asking "Right now, how strongly committed are you to doing this test, where 1 is undecided and 5 is very committed?". The followup interview measured commitment to screen again (for those who had returned their FOBT): "Now that you have done this screening test once, do you think you'll go on doing it every two years?" (yes/no answer) and "Right now, how strongly committed are you to doing this test again, where 1 is undecided and 5 is very committed?"

\subsubsection{Screening offer}

The screening package, or kit, included (a) a bowel cancer screening information pamphlet; (b) an immunochemical FOBT ((iFOBT also known as a faecal immunochemical test for haemoglobin [FIT], InSure ${ }^{\mathrm{TM}}$, Enterix Australia) that does not require dietary or drug restrictions; (c) a combined Participant Details and Consent Form confirming personal details, nominating a preferred doctor for follow-up, and consent to obtain clinical followup reports if required; and (d) a reply-paid return envelope.

\subsection{Data analysis}

Random missing values on pre- and post self efficacy (SE) variables $(17 / 2800,0.61 \%)$ were imputed using the expectation maximisation method, so that as many observations as possible were available for computing self efficacy total scores. The scores were split at the median baseline SE score of 17; scores $\leq 16$ were designated 'low' and scores $\geq 17$ 'high' SE. Participation rates were viewed as 'early' or 'late' at a cut-off point of 6 weeks following despatch of FOBT, at which time a reminder was sent to non-responders. Chi-square analysis was conducted to assess FOBT awareness, FOBT participation and return of implementation plans between groups; Fishers exact test was utilised where cells contained $<5$. Paired samples t-tests and one-way ANOVAs compared score means for self efficacy and commitment to screen. A median split was not performed for commitment to screen as the majority of people had high intention to screen. Binary logistic regression was used to examine the ability of self efficacy and commitment to screen to predict return of FOBT, and Generalised linear models (GLM) were used to assess interactions between variables. All tests were conducted using a two-sided alpha level of 0.05 .

\subsection{Results}

Recruitment and participation attrition rates are shown at Table 1. From a sampling frame of potential participants (3,000 men and 3,000 women), n=1642 were notified that they would 
be contacted and invited to participate. Of $n=994$ able to be contacted and eligible, $n=364$ individuals $(36.6 \%)$ agreed to participate in the study. Subsequently $n=14$ were excluded from analysis because they didn't receive an FOBT $(n=3)$; had undergone screening since joining the study $(n=4)$; reported symptoms that precluded them from using the FOBT $(n=4)$, or were unable to participate due to barriers unrelated to the study $(n=3)$. Baseline and screening participation data were therefore available for $n=350 / 994$ participants $(35 \%)$.

\begin{tabular}{|c|c|c|c|c|c|}
\hline & $\begin{array}{l}\text { Control } \\
\mathrm{N}=90 \\
(\%)\end{array}$ & $\begin{array}{l}\text { Aide to } \\
\text { retain } \\
n=79(\%)\end{array}$ & $\begin{array}{l}\text { Aide to } \\
\text { return } \\
n=91(\%)\end{array}$ & $\begin{array}{l}\text { Checklist to } \\
\text { return } \\
n=90(\%)\end{array}$ & $\begin{array}{l}\text { Test of } \\
\text { difference }\end{array}$ \\
\hline Male & $48(53)$ & $41(52)$ & $44(48)$ & $34(38)$ & $X^{2}(3)=5.270$, \\
\hline Female & 42 & 38 & 47 & 56 & $p=.153$ \\
\hline Age, mean & 61.1 & 60.5 & 61.2 & 61.7 & NS \\
\hline Age group $* *$ & & & & & $\begin{array}{l}X^{2}(6)=2.236, \\
p=.897\end{array}$ \\
\hline Age 50-59 & $43(48)$ & $38(48)$ & $45(49)$ & $37(41)$ & \\
\hline Age 60-69 & $31(34)$ & $29(37)$ & $32(35)$ & $39(43)$ & \\
\hline Age 70-76 & 15 (17) & $11(14)$ & $14(15)$ & $13(14)$ & \\
\hline $\begin{array}{l}\text { Highest level of } \\
\text { education }\end{array}$ & & & & & $\begin{array}{l}X^{2}(6)=5.894 \\
p=.435\end{array}$ \\
\hline Some high school & $46(51)$ & $35(45)$ & $39(43)$ & $52(58)$ & \\
\hline $\begin{array}{l}\text { Completed high } \\
\text { school/trade }\end{array}$ & $32(36)$ & $27(35)$ & $36(40)$ & $26(29)$ & \\
\hline University qualification & $12(13)$ & $16(20)$ & $16(18)$ & $12(13)$ & \\
\hline $\begin{array}{l}\text { Country of birth: } \\
\text { Australia }\end{array}$ & $67(74)$ & $57(72)$ & $71(78)$ & $61(68)$ & $\begin{array}{l}X^{2}(3)=2.539, \\
p=.468\end{array}$ \\
\hline $\begin{array}{l}\text { Never heard of FOBT } \\
\text { prior to participation }\end{array}$ & $64(71)$ & $65(82)$ & $59(65)^{\neq}$ & $65(72)$ & $\begin{array}{l}X^{2}(3)=5.618 \\
p=.132\end{array}$ \\
\hline
\end{tabular}

* percentages have been rounded so may not be equivalent to $100 \%$

$* * n=3$ missing values for age group

${ }^{\prime} \mathrm{n}=2$ missing values

Table 2. Study 1 Participant demographic characteristics*

At follow-up (post intervention and mailing of FOBT), n=13 participants declined or were unable to be interviewed and $n=9$ were unable to be contacted; follow-up data were therefore available for $n=328 / 994(33 \%)$ participants.

At recruitment, the groups ( $n=350$ participants) were balanced for gender, mean age, age group, level of education and Australian birth, and awareness of FOBT. The majority of participants had never heard of an FOBT before they were approached, i.e. they were in precontemplation stage (Table 2).

\subsubsection{FOBT participation}

Completed FOBTs were returned by $n=286 / 350$ (81.7\%) of eligible participants over a period of 15 weeks (mean = 3.12 weeks). Contrary to the hypothesis that formation of implementation plans would improve FOBT uptake, there was no significant difference 
between the groups in FOBT participation or return within 6 weeks (i.e., before and after reminder) (Table 3).

\begin{tabular}{|c|c|c|c|c|c|}
\hline & $\begin{array}{l}\text { Control } \\
\mathrm{N}=90(\%)\end{array}$ & $\begin{array}{l}\text { Aide to } \\
\text { retain } \\
n=79(\%)\end{array}$ & $\begin{array}{l}\text { Aide to } \\
\text { return } \\
n=91(\%)\end{array}$ & $\begin{array}{l}\text { Checklist to } \\
\text { return } \\
n=90(\%)\end{array}$ & $\begin{array}{l}\text { Test of } \\
\text { difference }\end{array}$ \\
\hline FOBTs returned & $76(84)$ & $66(84)$ & 70 (77) & $74(82)$ & $\begin{array}{l}X^{2}(3)=1.980 \\
p=.577\end{array}$ \\
\hline $\begin{array}{l}\text { Return of kits } \\
\text { within } 6 \text { weeks }\end{array}$ & $67(74)$ & $61(77)$ & $62(68)$ & $66(73)$ & $\begin{array}{l}\mathrm{X}^{2}(3)=.869 \\
\mathrm{p}=.833\end{array}$ \\
\hline Plans returned* & & & 62 & 66 & $\begin{array}{l}X^{2}(1)=.367 \\
p=.545\end{array}$ \\
\hline
\end{tabular}

*These numbers do not correspond with participants who returned FOBTs within 6 weeks

Table 3. Study 1 return of kits and implementation plans by group

\subsubsection{Return of implementation plans}

Most participants who returned a completed FOBT and were also required to return a completed implementation plan did so. There was no significant difference in rate of return between aide and checklist (Table 3), suggesting that differing levels of directedness had no impact on whether the plans were completed. There were no cases of a plan being returned without an accompanying completed kit.

\subsubsection{Self Efficacy (SE)}

A mixed between-within subjects analysis of variance was conducted to assess the impact of the different interventions on follow-up SE scores. There was no significant interaction between intervention group and time $[\mathrm{F}(3,324)=.874, \mathrm{p}=.455]$. There was a substantial main effect for time $[\mathrm{F}(1,324)=46.424, \mathrm{p}=<.005), \mathrm{\eta} 2=.125]$ with groups showing an increase in self efficacy (Time $1, \mathrm{M}=17.45, \mathrm{SD}=1.95$; Time $2, \mathrm{M}=18.3, \mathrm{SD}=1.91$ ). The main effect comparing the groups was not significant $[\mathrm{F}(3,324)=.156, \mathrm{p}=.93]$, suggesting that provision of assistance with planning did not influence SE (Table 4).

\begin{tabular}{lllll}
\hline & $\begin{array}{l}\text { Control } \\
\text { mean (SD) }\end{array}$ & $\begin{array}{l}\text { Aide to retain } \\
\text { mean (SD) }\end{array}$ & $\begin{array}{l}\text { Aide to return } \\
\text { mean (SD) }\end{array}$ & $\begin{array}{l}\text { Checklist to return } \\
\text { mean (SD) }\end{array}$ \\
\hline & & & & \\
Time 1 & $17.21(1.81)$ & $17.67(2.03)$ & $17.50(1.73)$ & $17.45(2.22)$ \\
Time 2 & $18.39(2.04)$ & $18.26(1.98)$ & $18.32(1.93)$ & $18.36(1.73)$ \\
\hline
\end{tabular}

Table 4. Study 1 group mean self efficacy scores pre- and post intervention

Subsequent analyses compared self-efficacy between those who returned FOBTs and those who did not. Table 5 shows that when we compared SE over time for FOBT non-returners using a paired samples t-test there was a decrease in confidence that approached significance $(p=.08)$. In other words, the confidence of non-participants to screen was impacted negatively by the provision of the FOBT. By contrast, confidence among those who returned an FOBT 
increased significantly, regardless of group assignment. This result suggests that, in general, confidence to complete the test in the future is likely to decrease for those people who don't complete initial screening, regardless of initial level of confidence.

\begin{tabular}{llllll}
\hline & & $\mathrm{M}$ & $\mathrm{SD}$ & $\mathrm{df}$ & $\mathrm{t}$ \\
SE score non-returners (full sample) & Time 1 & 16.77 & 1.893 & 47 & \multirow{2}{*}{1.758} \\
& Time 2 & 16.15 & 2.278 & & \\
& Time 1 & 17.57 & 1.944 & 279 & \multirow{2}{*}{$8.674^{* * *}$} \\
SE score returners (full sample) & Time 2 & 18.71 & 1.561 & & \\
Low baseline SE score non-returners & Time 1 & 15.46 & 1.208 & 25 & \multirow{2}{*}{0.220} \\
& Time 2 & 15.35 & 2.279 & & \\
Low baseline SE score returners & Time 1 & 15.69 & .978 & \multirow{2}{*}{116} & \multirow{2}{*}{$15.388^{* * *}$} \\
& Time 2 & 18.32 & 1.711 & & \\
High baseline SE score non-returners & Time 1 & 18.32 & 1.287 & \multirow{2}{*}{21} & \multirow{2}{*}{$2.752^{* *}$} \\
& Time 2 & 17.09 & 1.925 & & \\
High baseline SE score returners & Time 1 & 18.92 & 1.202 & \multirow{2}{*}{162} & \multirow{2}{*}{0.489} \\
\hline
\end{tabular}

$* * \mathrm{p}<.01$

$* * * \mathrm{p}<.001$

Table 5. Study 1 mean self efficacy scores pre- and post-intervention, overall and by return/non return of FOBTs

In order to determine whether confidence at baseline influenced reaction to the various interventions, participants were characterised as having a low or high SE score at baseline (determined by a median-split between 16 and 17), and change in confidence over time compared (See Table 5). Low SE non-returners did not significantly change their SE scores post intervention, whereas low SE returners' scores significantly increased post intervention. Similarly, for those with a high SE score at baseline, non-returners' scores significantly decreased post intervention but did not significantly change if they returned an FOBT. This latter result is likely to reflect ceiling effects given that the maximum score possible for SE was 20. These results suggest that self efficacy was increased when the test was completed but the initial level of confidence to complete the test was low, and conversely confidence was decreased when the initial level was high but the test was not completed.

\subsubsection{Commitment to screen and maintain screening}

At baseline, the majority of people $(n=217 / 343,63 \%)$ were committed or very committed to doing the test $(\mathrm{M}=4.39, \mathrm{SD}=.924$; median=5) and there were no group differences (Table 6). Those who returned an FOBT were asked their level of commitment to maintain screening, and just over half $(n=137 / 239,57.3 \%)$ were "very committed" to screening again $(M=4.38$, $\mathrm{SD}=.840$, median $=5, \mathrm{n}=47$ missing values), regardless of intervention assignment. For those that did return an FOBT, a paired-sample t-test indicated that for the sample as a whole there was a statistically significant decrease in commitment to screen from baseline, ie after exposure to the intervention and FOBT (Table 7). When we examined the relationship between commitment and self efficacy by comparing commitment level between those who had a low or high SE baseline score, it was apparent that the decrease in commitment came from those that had a high initial SE score (Table 7). 


\begin{tabular}{|c|c|c|c|c|c|c|}
\hline & $\begin{array}{l}\text { Control } \\
\text { mean } \\
(\mathrm{SD})\end{array}$ & $\begin{array}{l}\text { Aide to } \\
\text { retain } \\
\text { mean }(S D)\end{array}$ & $\begin{array}{l}\text { Aide to } \\
\text { return } \\
\text { mean (SD) }\end{array}$ & $\begin{array}{l}\text { Checklist to } \\
\text { return } \\
\text { mean (SD) }\end{array}$ & \multicolumn{2}{|c|}{ ANOVA } \\
\hline $\begin{array}{l}\text { Time } 1^{*} \\
(n=343)\end{array}$ & $4.48(.844)$ & $4.57(.854)$ & $4.33(.974)$ & $4.23(.984)$ & $\begin{array}{l}F,(\mathrm{df}) \\
2.21 \\
(3,339)\end{array}$ & $\begin{array}{l}\mathrm{p} \\
.087\end{array}$ \\
\hline $\begin{array}{l}\text { Time } 2^{* *} \\
(\mathrm{n}=239)\end{array}$ & $4.41(.938)$ & $4.33(.816)$ & $4.53(.704)$ & $4.24(.878)$ & $\begin{array}{l}1.25 \\
(3,235)\end{array}$ & .294 \\
\hline
\end{tabular}

*Includes non-returners and returners; 7/350 missing values

**Includes only those who returned an FOBT; 47/286 missing values

Table 6. Study 1 mean commitment to screen by group pre- and post intervention

\begin{tabular}{|c|c|c|c|c|c|}
\hline & & M & SD & $\mathrm{df}$ & $t$ \\
\hline \multirow{2}{*}{ Commitment to screen (full sample, n=233) } & Time 1 & 4.52 & 0.804 & \multirow{2}{*}{232} & \multirow{2}{*}{$2.15^{*}$} \\
\hline & Time 2 & 4.38 & 0.843 & & \\
\hline \multirow{2}{*}{$\begin{array}{l}\text { Low baseline SE score commitment to screen } \\
(\mathrm{n}=99)\end{array}$} & Time 1 & 4.20 & 0.947 & \multirow{2}{*}{98} & \multirow{2}{*}{-1.522} \\
\hline & Time 2 & 4.36 & 0.814 & & \\
\hline \multirow{2}{*}{$\begin{array}{l}\text { High baseline SE score commitment to screen } \\
(\mathrm{n}=134)\end{array}$} & Time 1 & 4.76 & 0.578 & \multirow[b]{2}{*}{133} & \multirow{2}{*}{$4.485^{* * *}$} \\
\hline & Time 2 & 4.39 & 0.866 & & \\
\hline
\end{tabular}

$*<.05$

$* * *<.001$

Table 7. Study 1 FOBT returners' commitment to screen pre- and post-intervention, overall and by SE level at baseline

\subsubsection{Effect of self efficacy and commitment to screen on use of FOBT}

Logistic regression was used to assess the independent and joint effects of baseline SE and baseline commitment to screen on return of FOBT. SE alone made a statistically significant contribution, $\left.\mathrm{X}^{2}(1, \mathrm{n}=350)=11.535, \mathrm{p}<.001, \mathrm{OR}=1.27, \mathrm{CI} 1.10-1.47\right)$, predicting $5.3 \%$ of the variance (Nagelkerke $\mathrm{R}$ squared) in screening uptake. Commitment to screen alone also made a statistically significant contribution $X^{2}(1, n=343)=13.837, p<001, O R=1.67, C I 1.28$ 2.18 ), and explained $6.4 \%$ of the variance. When these predictors were entered together into the logistic regression model, there was a statistically significant effect, $X^{2}(2, n=343)=17.487$, $\mathrm{p}<.001$ ), but only commitment to screen displayed a unique and statistically significant contribution ( $\mathrm{p}=.012, \mathrm{OR}=1.46, \mathrm{CI} 1.07-1.97)$; baseline self efficacy was marginally significant $(p=.06, O R=1.17, C I .993-1.37)$. This suggests that those who are committed to using the FOBT will do so regardless of their level of confidence. The total variance explained by the combined model was $\mathrm{R}^{2}=8.0 \%$, indicating that factors other than these also contribute to the likelihood of completing an FOBT.

\section{Study 2}

Study 2 was conducted to examine the generalisability of Study 1's results to the broader population. This approach more closely approximated that undertaken in current population screening programs utilising FOBTs. 


\subsection{Methods}

\subsubsection{Sample size and selection}

Sample selection proceeded as described for Study 1. A separate sample of 6000 men and women aged between 50 and 76 years, randomly selected from four South Australian electoral divisions, was obtained from the AEC. People residing in postcodes included in the pilot NBCSP were omitted from the sample, as were those whose address indicated they resided in a hostel or nursing home. The remaining sample was randomised separately by sex and 400 men and women were assigned sequentially to one of 4 groups. In total 1600 names were allocated.

\subsubsection{Study conduct}

Phase 1: All potential participants were mailed an advance notification letter (which aligns with the protocol adopted by the NBCSP) and accompanying information as for Study 1, and were informed that they would shortly be receiving a screening package in the mail. Exclusion due to ineligibility was dependent upon self-identification and communication of this fact to the researchers before despatch of FOBT. Willingness to participate was not deliberately ascertained.

Phase 2: Three weeks after the advance notification letter, a screening kit including an immunochemical FOBT was sent to individuals. As for Study 1, intervention groups also received a discrete implementation plan. The nature of this approach precluded us from ascertaining willingness to participate and from obtaining pre- and post measures of self efficacy and commitment to screening.

Phase 3: Receipt of completed FOBTs was recorded by the Bowel Health Service and participation data relayed to the researchers.

\subsubsection{Data analysis}

Participation rates were viewed as 'early' or 'late' at a cut-off point of 6 weeks following despatch of FOBT, when a reminder was sent to non-responders. Chi-square analysis was conducted to assess FOBT participation between groups.

\subsection{Results}

$\mathrm{N}=1600$ men and women were sent an advance warning letter. Those who did not identify themselves as ineligible or not wishing to participate were then mailed a screening kit and accompanying material according to intervention group. In total, $\mathrm{n}=225$ were excluded from the study ( $n=118$ identified themselves as ineligible; $n=83$ didn't wish to participate; $n=24$ packages were undeliverable). Analyses were therefore conducted for $n=1375$ men and women. Recruitment and participation attrition rates are shown at Table 8 .

At baseline, the groups were balanced for gender (Table 9). It wasn't possible to ascertain age group breakdowns because the AEC supplied a random sample within an age range (50-74 years) which wasn't broken down into groups (for Study 1 we ascertained age from the participant). The study design also precluded us obtaining other demographic information (mean age, education, country of birth) as we did for Study 1 . However, given that the underlying sampling mechanism was identical (i.e., supplied by the AEC), there is some confidence that the groups were balanced on these other factors. 


\begin{tabular}{|c|c|c|}
\hline $\begin{array}{l}\text { Recruitment } \\
\text { Phase } 1\end{array}$ & $\begin{array}{l}\text { Interventions } \\
\text { Phase } 2\end{array}$ & $\begin{array}{l}\text { Measures } \\
\text { Phase } 3\end{array}$ \\
\hline $\begin{array}{l}\mathrm{N}=1600 \\
\text { Potentially eligible } \\
\text { participants } \\
\text { randomised to } \\
\text { study arm then } \\
\text { mailed information } \\
\text { sheet and } \\
\text { notification that } \\
\text { they would shortly } \\
\text { receive an FOBT } \\
\text { kit. Ineligibility } \\
\text { was defined and } \\
\text { dependent upon } \\
\text { self-report }\end{array}$ & $\begin{array}{l}\text { Control } \\
\text { FOBT screening package only }(\mathrm{n}=400) \\
\text { Aide to retain } \\
\text { FOBT screening package }+ \text { implementation plan to } \\
\text { be formulated and retained by participant }(\mathrm{n}=400)\end{array}$ & $\begin{array}{l}\text { (All groups, } \\
n=1375 \text { ) } \\
\text { Return of kit } \\
\text { within and } \\
\text { after } 6 \text { weeks }\end{array}$ \\
\hline
\end{tabular}

Table 8 . Study 2 interventions by phase and arm, with attrition rates

\begin{tabular}{l|l|l|l|l|l}
\hline & $\begin{array}{l}\text { Control) } \\
\mathrm{n}=345(\%)\end{array}$ & $\begin{array}{l}\text { Aide to } \\
\text { retain } \\
\mathrm{n}=350(\%)\end{array}$ & $\begin{array}{l}\text { Aide to } \\
\text { return } \\
\mathrm{n}=334(\%)\end{array}$ & $\begin{array}{l}\text { Checklist to } \\
\text { return } \\
\mathrm{n}=346(\%)\end{array}$ & $\begin{array}{l}\text { Test of } \\
\text { difference }\end{array}$ \\
\hline $\begin{array}{l}\text { Male } \\
\text { Female }\end{array}$ & $176(51.0)$ & $\begin{array}{l}176(50.3) \\
174\end{array}$ & $\begin{array}{l}170(50.9) \\
164\end{array}$ & $\begin{array}{l}178(51.4) \\
168\end{array}$ & $\begin{array}{l}X^{2}(3)=0.96, \\
\mathrm{p}=.992\end{array}$ \\
\hline
\end{tabular}

Table 9. Study 2 participant demographic characteristics

\subsubsection{FOBT participation}

Completed FOBTs were returned by 548/1375 (39.9\%) of participants over a period of 26 weeks (mean $=5.51$ weeks). This rate is similar to that achieved in the NBCSP in 2008 (i.e., $41 \%$ (AIHW, 2010). As for Study 1, contrary to our hypothesis that the formation of implementation plans would improve FOBT uptake, there was no significant difference between the groups in FOBT participation or return within 6 weeks (before and after reminder) (Table 10).

\begin{tabular}{|c|c|c|c|c|c|}
\hline & $\begin{array}{l}\text { Control } \\
n=345(\%)\end{array}$ & $\begin{array}{l}\text { Aide to } \\
\text { retain } \\
n=350(\%)\end{array}$ & $\begin{array}{l}\text { Aide to } \\
\text { return } \\
n=334(\%)\end{array}$ & $\begin{array}{l}\text { Checklist to } \\
\text { return } \\
\mathrm{n}=346(\%)\end{array}$ & $\begin{array}{l}\text { Test of } \\
\text { difference }\end{array}$ \\
\hline FOBTs returned & $144(41.7)$ & $131(37.4)$ & $131(39.2)$ & $142(41.0)$ & $\begin{array}{l}X^{2}(3)=1.633 \\
p=.652\end{array}$ \\
\hline $\begin{array}{l}\text { Return of kits } \\
\text { within } 6 \text { weeks }\end{array}$ & $106(30.7)$ & $98(28.0)$ & $97(29.0)$ & $94(27.2)$ & $\begin{array}{l}X^{2}(3)=3.269 \\
p=.352\end{array}$ \\
\hline $\begin{array}{l}\text { Return of plans } \\
\text { with FOBT }\end{array}$ & & & $\begin{array}{l}83 / 131 \\
(58.4)\end{array}$ & $62 / 142$ (43.6) & $\begin{array}{l}X^{2}(1)=9.389 \\
p=.001\end{array}$ \\
\hline
\end{tabular}

Table 10. Study 2 overall return of kits and within 6 weeks (i.e. before reminder) by group 


\subsubsection{Return of implementation plans}

A considerable proportion of those who returned an FOBT and were also required to return a completed implementation plan did not do so, and significantly fewer people returned the prescriptive plan (i.e., checklist) than the aide (Table 10), suggesting that level of directedness may have an effect on whether the plans were completed-those who were required to formulate their own plan based on suggestions for action were more likely to return a plan compared to those given a prescriptive checklist. Notwithstanding this result, given that the requirement for return was to act as an indicator of whether plans had actually been formulated, it appears that around half the participants used the FOBT without adhering to planning instructions, particularly those who received a prescriptive plan.

\section{Discussion}

We hypothesised that the formation of implementation plans would assist return of FOBT kits by providing a physical cue to action. In addition we hypothesised that the process of completing a plan would increase confidence in ability to complete the test and that those who were strongly committed to screening at baseline would differ in formation of implementation plans and participation to those with a less strong initial commitment.

Notwithstanding the difference in overall participation figures between Study $1(81.7 \%)$ and Study $2(39.9 \%)$, we found that for both studies provision of assistance with planning, regardless of directedness, had no influence on completion of an FOBT. The lack of influence of an implementation plan concurs with the conclusions of other researchers who have also found no effect of implementation planning on subsequent behaviour (Jackson et al., 2005; Michie et al., 2004; Rutter et al., 2006; Skar et al., 2011). Even so, this result goes against the large body of evidence suggesting that formulating action plans has a positive effect on the intention-behaviour gap. It has been suggested, however, that there exists sparse evidence for a positive effect of implementation intentions on behaviours outside student samples, who are more likely to comply with task demands (actually formulating the plan) (Jackson et al., 2005; Schweiger Gallo \& Gollwitzer, 2007). It has also been argued that implementation plans are only effective where there is motivation to achieve a goal (Sniehotta, 2009) and that where goal intentions are positive, so will be the effects of implementation intentions (Gollwitzer, 1993; Oettingen et al., 2000). The majority of FOBT returners in Study 1 already had a high intention to screen, which may be attributable to the fact that that they had made a conscious decision to participate and were presumably more motivated to act, but in any case there was no evidence of a differential effect of combining high commitment with formation of implementation plans on FOBT return. Indeed, the high proportion of implementation plans returned by Study 1 participants (82\%) may be indicative only of compliance with the study requirements (i.e., to return plans) rather than evidence of the use of these plans.

However, and in contrast to Study 1, it is evident that nearly half the FOBTs returned in Study 2 were completed without making a plan, a result which could reasonably be extrapolated to the group that was asked to retain their formulated plan. It has been suggested that non-completion may reflect ambiguity of study instructions (Michie et al., 2004) but, given that nearly all Study 1 participants returned identically-constructed implementation plans with a completed FOBT, this was not the case in our population. Rather, this outcome suggests that some felt they had no need to complete plans, perhaps because their intentions were sufficiently strong to make the use of plans unnecessary. 
Indeed, we found from Study 1 that commitment had the most significant influence on FOBT use-because the majority of participants were strongly committed, we were unable to determine if having a weak level of commitment would influence formulation of an implementation plan or use of the FOBT. Of those Study 2 participants that did formulate and return plans, significantly fewer used the prescriptive 'checklist' format. Participants may have been "turned off" by the directedness of the checklist, particularly since they were a population sample and had not made a mindful decision to participate in a study. Study 1 demonstrated that provision of directions did not increase people's self efficacy. These results accord with a meta-analysis of 66 randomised controlled studies that concluded that forming implementation intentions had negligible effects on self efficacy and goal intentions (Webb \& Sheeran, 2008).

For the group as a whole, baseline self efficacy did not have a strong influence on whether people used the test; rather, the act itself of completing the FOBT determined confidence-self efficacy was increased when the initial level of confidence to complete the FOBT was low, and conversely confidence was decreased when the initial level was high but the test was not completed. Rather than confidence to use the FOBT, from Study 1 it appears that being initially committed to screening had a more significant influence on whether people actually did use the FOBT, confirming the general consensus that intention to perform a behaviour is a necessary precursor of action. Even so, we found in Study 1 that commitment to screening, while a significant predictor of FOBT use, in conjunction with self efficacy explained only $8.0 \%$ of the variance, indicating that other factors exist which contribute to the likelihood of completing an FOBT. For example, Gregory et al. (2011) found that social-cognitive predictors of intention to screen for CRC and actual screening behaviour, although overlapping, were not the same, and Power and colleagues (2008) in their study of CRC screening found that life difficulty variables were better predictors of action than intention.

It is puzzling to note that there was a significant decrease in commitment to repeat screening by those that did use the FOBT and had a high initial level of confidence, in contrast to those with low confidence whose level of commitment to screening did not change. It may be that initial commitment was high for most because the participants were an 'interested' sample, and that those with high SE who screened reinforced their view that they were capable of completing an FOBT without necessarily moving from that conclusion and forming a commitment to rescreen. Conversely, those with low confidence but who did complete their test, thereby increasing their confidence, could have felt 'motivated' to repeat the experience again and so not changed their level of commitment. Interestingly, the same lessening of intention by those with high self efficacy was noted in a study examining the role of self efficacy in testicular self-examination (Umeh \& Chadwick, 2010). The researchers found that those with high self efficacy appeared to have worsened attitudes toward self examination when both vulnerability and severity estimates were low. The same situation could well apply to CRC screening, particularly as perceived susceptibility is a Preventive Health Model (PHM) construct demonstrated to be associated with CRC screening ((Flight et al., 2010; Tiro et al., 2005). Commitment to future CRC screening in one or 2 years would perhaps, as Umeh and Chadwick (2010) have suggested, be temporarily rejected if the penalties of inaction are deemed insignificant, a viewpoint which may stem from a defensive reaction activated by anxiety. This view suggests that an emphasis on the development of messages designed to increase perceptions of personal risk of CRC without raising anxiety are warranted. 
The low rate of participation in Study 2 may reflect a dissonance of messages appropriate to an individual's stage of readiness to screen (Prochaska, 2008). The differences in study design, particularly recruitment strategy, between studies 1 and 2 may have resulted in basic sample differences in stage of readiness to screen at baseline. Specifically, including only participants prepared to complete questionnaires in Study 1 resulted in a highly committed sample, likely to be in contemplation or preparation to act stage, characterised by a high participation rate. By contrast, Study 2 invitees were a population sample, most of who were probably in pre-contemplation on receipt of the FOBT, with participation rates comparable with those achieved by the national screening program (i.e. 40\%). Precontemplation is a stage where it could be argued that a person's knowledge, attitudes and intentions are in a more unstable state. People in this stage have been shown to have higher barriers, higher chance health locus of control, low powerful others health locus of control, lower perceived susceptibility and lower CRC knowledge (Gregory et al., 2011). It follows that these factors should be addressed to facilitate movement through contemplation to the action stage. However, our implementation plans as formulated were aimed at those with an intention to act and focused on the where, when and how of successful completion of the FOBT. It could be daunting for those who had never heard of FOBT screening to receive a test and accompanying material designed to assist with completing the test without first being given information aimed at overcoming barriers and lack of knowledge associated with the pre-contemplation stage.

\section{Conclusion}

The provision of assistance with the preparation of implementation plans, regardless of their level of directedness, had no influence on FOBT participation in the 2 studies conducted. One reason for their lack of effect may be that the majority of participants were likely to be in pre-contemplation stage in Study 2 and in the action stage in Study 1. Thus ceiling effects limited the potential for cues to impact behaviour among participants in Study 1, and Study 2 participants may have benefited from an intervention that tackled Contemplation as an intermediary to Action. This stage mismatch has implications for population-based screening programs and may contribute toward less than optimal screening uptake rates. Future research could usefully address the potential for the communication within a population setting of material targeted to specific decision stages, designed to progressively move an individual toward action and maintenance of action. Our research indicated that confidence to screen and commitment to screen separately and together exerted a greater influence on actual FOBT participation; however, these factors accounted for a small amount of variance and future research should address the contribution of other factors.

\section{Acknowledgements}

We would like to thank Ian Zajac, CSIRO, for timely statistical advice.

\section{References}

AIHW. (2010). National Bowel Cancer Screening Program: Annual monitoring report 2009; Data supplement 2010. Canberra: Australian Institute of Health and Welfare \& Australian Department of Health and Ageing 
Ajzen, I. (1985). From intentions to actions: A theory of planned behavior. In: Action-Control: From cognition to behavior, J. Kuhl \& J. Beckman (Eds.), (pp. 11-39), ISBN 978-0387134-451, Heidelberg, Germany: Springer

Bagozzi, R. \& Warshaw, P. (1990). Trying to consume. Journal of Consumer Research, Vol. 17, pp. 127-140, ISSN 0093-5301

Becker, M.; Haefner, D. \& Maiman, L. (1977). The health belief model in the prediction of dietary compliance: A field experiment. Journal of Health and Social Behaviour, Vol. 18, pp. 348-366, ISSN 0022-1465

Conner, M. \& Norman, P. (Eds.). (2005). Predicting Health Behaviour: Research and Practice with Social Cognition Models (2nd ed.). ISBN 13978033521176 0, Maidenhead, UK: Open University Press

DeVellis, B., Blalock, S.J. \& Sandler, R. (1990). Predicting participation in cancer screening: The role of perceived behavioural control. Journal of Applied Social Psychology, Vol. 20, pp. 639-660, ISSN 0021-9010

Fisher, J.; Fikry, C. \& Troxel, A. (2006). Cutting Cost and Increasing Access to Colorectal Cancer Screening: Another Approach to Following the Guidelines. Cancer Epidemiology Biomarkers \& Prevention, Vol. 15, No. 1, pp. 108-113, ISSN 1055-9965

Flight, I.; Wilson, C.; McGillivray, J. \& Myers, R. (2010). Cross-cultural validation of the Preventive Health Model for colorectal cancer screening: An Australian study. Health Education \& Behavior, Vol. 37, No. 5, pp. 724-736, ISSN 1090-1981

Frazier, A.; Colditz, G.; Fuchs, C. \& Kuntz, K. (2000). Cost-effectiveness of screening for colorctal cancer in the general population. JAMA, Vol. 284, pp. 1954-1961, ISSN 0098-7484

Gollwitzer, P. (1993). Goal achievement: The role of intentions. European Review of Social Psychology, Vol. 4, pp. 141-185, ISSN 1046-3283

Gollwitzer, P. \& Sheeran, P. (2006). Implementation intentions and goal achievement: A meta-analysis of effects and processes. Advances in Experimental Social Psychology, Vol. 38, pp. 69-119, ISSN 0065-2601

Gregory, T.; Wilson, C.; Duncan, A.; Turnbull, D.; Cole, S. \& Young, G. (2011). Demographic, social cognitive and social ecological predictors of intention and participation in screening for colorectal cancer. BMC Public Health, Vol. 11, pp. 38, ISSN 1471-2458

Hardcastle, J.; Chamberlain, J.; Robinson, M.; Moss, S.; Amar, S.; Balfour, T.; James, P. \& Mangham, C. (1996). Randomised controlled trial of faecal-occult-blood screening for colorectal cancer. Lancet, Vol. 348, pp. 1472-1477, ISSN 0099-5355

Hewitson, P.; Glasziou, P.; Irwig, L.; Towler, B. \& Watson, E. (2007). Screening for colorectal cancer using the faecal occult blood test, Hemoccult: Cochrane Database of Systematic Reviews Issue 1. Art. No.: CD001216. DOI: 10.1002/14651858.CD001216.pub2

International Cancer Screening Network. (2008). Inventory of Colorectal Cancer Screening Activities in ICSN Countries, May 2008. Retrieved 22 June 2011, from http://www.appliedresearch.cancer.gov/icsn/colorectal/screening.html

Jackson, C.; Lawton, R.; Knapp, P.; Ranor, D.; Conner, M.; Lowe, C. \& Closs, S. (2005). Beyond intention: do specific plans increase health behaviours in patients in primary care? A study of fruit and vegetable consumption. Social Science $\mathcal{E}$ Medicine, Vol. 60, pp. 2382-2391, ISSN 0037-7856

Jemal, A.; Bray, F.; Center, M.; Ferlay, J.; Ward, E. \& Forman, D. (2011). Global Cancer Statistics. CA: A Cancer Journal for Clinicians, Vol. 61, pp. 69-90, ISSN 0007-9235

Kronborg, D.; Jorgensen, O.; Fenger, C. \& Rasmussen, M. (2004). Randomized study of biennial screening with a faecal occult blood test: results after nine screening 
rounds. Scandinavian Journal of Gastroenterology, Vol. 39, No. 9, pp. 846-851, ISSN 0036-5521

Lechner, L.; Oenema, A. \& Nooijer, J. (2002). Testicular self-examination (TSE) among Dutch young men aged 15-19: Determinants of the intention to practice TSE. Health Education Research, Vol. 17, pp. 73-84, ISSN 0268-1153

Luszczynska, A. (2004). Change in breast self-examination behavior: Effects of intervention on enhancing self-efficacy. International Journal of Behavioral Medicine, Vol. 11, No. 2, pp. 95-103, ISSN 1070-5503

Mandel, J.; Bond, J.; Church, T.; Snover, D.; Bradley, G.; Schuman, L. \& Ederer, F. (1993). Reducing mortality from colorectal cancer by screening for fecal occult blood. Minnesota Colon Cancer Control Study. New England Journal of Medicine, Vol. 328, No. 19, pp. 1365-1371, ISSN 0028-4793

Mandel, J.; Church, T.; Bond, J.; Ederer, F.; Geisser, M.; Mongin, S.; Snover, D. \& Schuman, L. (2000). The effect of fecal occult-blood screening on the incidence of colorectal cancer. New England Journal of Medicine, Vol. 343, No. 22, pp. 1603-1607, ISSN 0028-4793

Michie, S.; Dormandy, E. \& Marteau, T. (2004). Increasing screening uptake amongst those intending to be screened: the use of action plans. Patient Education and Counseling, Vol. 55, pp. 218-222, ISSN 0738-3991

Milne, S.; Orbell, S. \& Sheeran, P. (2002). Combining motivational and volitional interventions to promote exercise participation: Protection motivation theory and implementation intentions. British Journal of Health Psychology, Vol. 7, pp. 183-184, ISSN 1359-107X

Oettingen, G.; Honig, G. \& Gollwitzer, P. (2000). Effective self-regulation of goal attainment. International Journal of Educational Research, Vol. 33, pp. 705-732, ISSN:0883-0355

Orbell, S.; Hodgins, S. \& Sheeran, P. (1997). Implementation intentions and the theory of planned behaviour. Personality and Social Psyschology Bulletin, Vol. 23, pp. 945-954, ISSN 0146-1672

Power, E., Van Jaarsveld, C.H.M., McCaffery, K., Miles, A., Atkin, W. \& Wardle, J. (2008). Understanding intentions and action in colorectal cancer screening. Annals of Behavioral Medicine, Vol. 35, pp. 285-294, ISSN 0883-6612

Prochaska, J. (2008). Decision making in the Transtheoretical Model of Behavior Change. Medical Decision Making, Vol. 28, pp. 845-849, ISSN 0272-989X

Prochaska, J.; Velicer, W.; DiClemente, C. \& Fava, J. (1988). Measuring processes of change: applications to the cessation of smoking. Journal of Consulting and Clinical Psychology, Vol. 56, No. 4, pp. 520-528, ISSN 0022-006X

Rutter, D.; Steadman, L. \& Quine, L. (2006). An implementations intervention to increase uptake of mammography. Annals of Behavioural Medicine, Vol. 32, No. 2, pp. 127134, ISSN 0883-6612

Schwarzer, R. \& Fuchs, R. (1995). Self-efficacy and health behaviours. In:Predicting health behavior: Research and practice with social cognition models, M. Conner \& P. Norman (Eds.), (pp. 163-196). ISBN 033519320X, Buckingham, UK: Open University Press

Schweiger Gallo, I. \& Gollwitzer, P. (2007). Implementation intentions: A look back at fifteen years of progress. Psicothema, Vol. 19, No. 1, pp. 37-42, ISSN 0214-9915

Sheeran, P. (2002). Intention-behavior relations: A conceptual and empirical review. European Review of Social Psychology, Vol. 12, No. 1, pp. 1-36, ISSN 1046-3283

Sheeran, P. \& Orbell, S. (2000). Using implementation intentions to increase attendance for cervical cancer screening. Health Psychology, Vol. 19, pp. 283-289, ISSN 0278-6133

Skar, S.; Sniehotta, F.; Molloy, G.; Prestwich, A. \& Araujo-Soares, V. (2011). Do brief online planning intereventions increase physical activity amongst university students? A 
randomised controlled trial. Psychology and Health, Vol. 26, No. 4, pp. 399-417, ISSN 0887-0446

Sniehotta, F. (2009). towards a theory of intentional behaviour change: Plans, planning, and self-regulation. British Journal of Health Psychology, Vol. 14, No., pp. 261-273, ISSN 1359-107X

Tiro, J.; Vernon, S.; Hyslop, T. \& Myers, R. (2005). Factorial validity and invariance of a survey measuring psychosocial correlates of colorectal cancer screening among African Americans and Caucasians. Cancer Epidemiology Biomarkers E Prevention, Vol. 14, pp. 2855-286, ISSN 1573-3521

Umeh, K. \& Chadwick, R. (2010). Early detection of testicular cancer: revsiting the role of self-efficacy in testicular self-examination among young asymptomatic males [Epub ahead of print]. Journal of Behavioral Medicine, published online 22 April 2010, ISSN 1573-3521

Vernon, S.; Myers, R. \& Tilley, B. (1997). Development and validation of an instrument to measure factors related to colorectal cancer screening adherence. Cancer Epidemiology Biomarkers \& Prevention, Vol. 12, pp. 339-349, ISSN 1573-3521

Verplanken, B. \& Faes, S. (1999). Good intentions, bad habits, and effects of forming implementation intentions on healthy eating. European Review of Social Psychology, Vol. 29, pp. 592-604, ISSN 1046-3283

Webb, T. \& Sheeran, P. (2006). Does changing behavioral intentions engender behavior change? A meta-analysis of the experimental evidence. Psychological Bulletin, Vol. 132, No. 2, pp. 249-268, ISSN 0033-2909

Webb, T. \& Sheeran, P. (2008). Mechanisms of implementation intention effects: The role of goal intentions, self-efficacy, and accessibility of plan components. British Journal of Social Psychology, Vol. 47, pp. 373-395, ISSN 2044-8309

Weller, D.; Moss, S.; Butler, P.; Campbell, C.; Coleman, D.; Melia, J. \& Robertson, R. (2006). English Pilot of Bowel Cancer Screening: an evaluation of the second round. Final Report to the Department of Health. Edinburgh: University of Edinburgh. UK. 


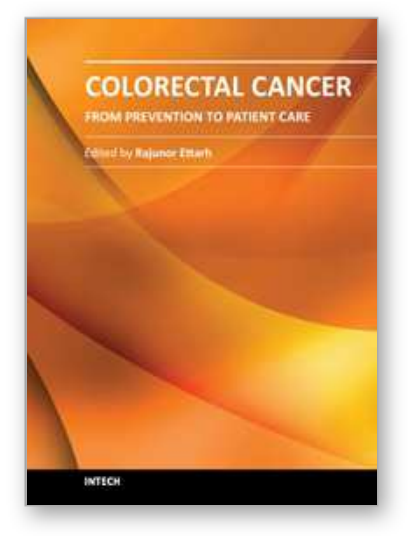

\author{
Colorectal Cancer - From Prevention to Patient Care \\ Edited by Dr. Rajunor Ettarh
}

ISBN 978-953-51-0028-7

Hard cover, 538 pages

Publisher InTech

Published online 17, February, 2012

Published in print edition February, 2012

The projections for future growth in the number of new patients with colorectal cancer in most parts of the world remain unfavorable. When we consider the substantial morbidity and mortality that accompanies the disease, the acute need for improvements and better solutions in patient care becomes evident. This volume, organized in five sections, represents a synopsis of the significant efforts from scientists, clinicians and investigators towards finding improvements in different patient care aspects including nutrition, diagnostic approaches, treatment strategies with the addition of some novel therapeutic approaches, and prevention. For scientists involved in investigations that explore fundamental cellular events in colorectal cancer, this volume provides a framework for translational integration of cell biological and clinical information. Clinicians as well as other healthcare professionals involved in patient management for colorectal cancer will find this volume useful.

\title{
How to reference
}

In order to correctly reference this scholarly work, feel free to copy and paste the following:

Ingrid Flight, Carlene Wilson and Jane McGillivray (2012). Turning Intention Into Behaviour: The Effect of Providing Cues to Action on Participation Rates for Colorectal Cancer Screening, Colorectal Cancer - From Prevention to Patient Care, Dr. Rajunor Ettarh (Ed.), ISBN: 978-953-51-0028-7, InTech, Available from: http://www.intechopen.com/books/colorectal-cancer-from-prevention-to-patient-care/turning-intention-intobehaviour-the-effect-of-providing-cues-to-action-on-participation-rates-for-c

\section{INTECH}

open science | open minds

\section{InTech Europe}

University Campus STeP Ri

Slavka Krautzeka 83/A

51000 Rijeka, Croatia

Phone: +385 (51) 770447

Fax: +385 (51) 686166

www.intechopen.com

\section{InTech China}

Unit 405, Office Block, Hotel Equatorial Shanghai

No.65, Yan An Road (West), Shanghai, 200040, China

中国上海市延安西路65号上海国际贵都大饭店办公楼 405 单元

Phone: +86-21-62489820

Fax: $+86-21-62489821$ 
(C) 2012 The Author(s). Licensee IntechOpen. This is an open access article distributed under the terms of the Creative Commons Attribution 3.0 License, which permits unrestricted use, distribution, and reproduction in any medium, provided the original work is properly cited. 